\title{
Deaf culture and health care
}

\author{
Mary Malebranche MD, Kevin Morisod MD, Patrick Bodenmann MD
}

Cite as: CMAJ 2020 December 14;192:E1809. doi: 10.1503/cmaj.200772

\section{Being part of the Deaf community is not the same as having \\ 1 hearing impairment}

About 357000 Canadians identify as being part of the Deaf community (capital-D "Deaf"), a distinct cultural and linguistic minority that uses sign language to communicate and for whom deafness is an alternative state, not a disability requiring correction. ${ }^{1}$ In contrast, about 3.2 million Canadians have hearing impairment, some of whom have severe to profound hearing loss (lower-case d "deaf").

2

Members of the Deaf community experience worse mental health, cardiovascular and sexual health outcomes than nonDeaf individuals ${ }^{2,3}$

Given limited access to hearing-based mass media, ambient conversations and public health messaging, members of the Deaf community are up to 6.9 times more likely than non-deaf individuals to have inadequate health literacy. ${ }^{4}$ Deaf sign language users have significantly lower cardiovascular health knowledge than non-deaf individuals. ${ }^{4}$

Not all people with severe to profound hearing loss are fluent in sign language

Each person's preferred mode of communication, which may include lip reading, written communication, visual aids or sign language, should be confirmed. If sign language is preferred, an interpreter should be available. ${ }^{4}$ It is preferable not to assume that Deaf individuals have effective lip-reading skills, as their comprehension may be as low as $30 \% .^{2}$

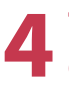

Technological advances can be leveraged to improve communication with Deaf individuals

Integrating innovations for sign language interpretation into clinical care, such as KinTrans (www.kintrans.com) and Sign-Speak (sign -speak.com), have substantial potential to improve communication with sign language users. ${ }^{5}$

\section{5}

The availability of cochlear implantation has raised concerns about its impact on Deaf cultural identity

Although cochlear implants are associated with improved audition and spoken language development, their effect on cultural identity, social participation and well-being among Deaf individuals remains controversial. For example, integrating Deaf children with cochlear implants into standard schools has caused a decline in specialized deaf schools. ${ }^{6}$

\section{References}

1. Statistics on Deaf Canadians. Ottawa: The Canadian Association of the Deaf - Association des Sourds du Canada; 2015 Available: cad.ca/issues-positions/statistics-on-deaf-canadians/ (accessed 2020 Apr. 15).

2. Fellinger J, Holzinger D, Pollard R. Mental health of deaf people. Lancet 2012;379:1037-44.

3. Emond $\mathrm{A}$, Ridd $\mathrm{M}$, Sutherland $\mathrm{H}$, et al. Access to primary care affects the health of Deaf people. Br J Gen Pract 2015;65:95-6.

4. McKee MM, Paasche-Orlow MK, Winters PC, et al. Assessing health literacy in deaf American sign language users. $J$ Health Commun 2015;20:92-100.

5. Smeijers A, Ens-Dokkum MH, van den Bogaerde B, et al. Availability of specialised healthcare facilities for deaf and hard of hearing individuals. International Journal on Mental Health and Deafness 2018;4:14-27.

6. Chapman M, Dammeyer J. The relationship between cochlear implants and deaf identity. Am Ann Deaf 2017;162:319-32.

\section{Competing interests: None declared.}

This article has been peer reviewed.

Affiliations: Department of Vulnerabilites and Social Medicine (Malebranche, Morisod, Bodenmann), University Center for General Medicine and Public Health, University of Lausanne, Lausanne, Switzerland; Department of Medicine (Malebranche), Cumming School of Medicine, University of Calgary, Calgary, Alta.

Acknowledgements: The authors acknowledge the intellectual contributions provided by Dr. Laurent Frikart, an otorhinolaryngologist who works with Deaf and hearing-impaired individuals in Lausanne, Switzerland. They also acknowledge the intellectual contributions of Stéphane Beyeler, a Deaf sign language user who identifies as a member of the Deaf community in Lausanne and also serves as director of the French-speaking region of the Swiss Federation of the Deaf. Both reviewed and provided valuable intellectual content on a revised version of the manuscript.

Correspondence to: Mary Malebranche, mary.malebranche@ucalgary.ca 